\title{
Equidad, cohesión y economía social
}

\author{
Equity, cohesion and social economy \\ Marcos DE CASTRO SANZ \\ Confederación Empresarial Española de la Economía Social \\ mdecastrosanz@gmail.com
}

Durante la «recuperación» de 2009 y 2010,

el 1 por ciento de los estadounidenses con mayores ingresos se quedó con el 93 por ciento del aumento de la renta.

Otros indicadores de desigualdad

(como la riqueza, la salud, la expectativa de vida) son tan malos o, incluso peores.

Hay una clara tendencia a la concentración de ingresos y riqueza en la cima, al vaciamiento de las capas medias y a un aumento de la pobreza en el fondo.

Sería distinto si los altos ingresos de los que están arriba se debieran a que contribuyeron más a la sociedad.

Pero la Gran Recesión demostró que no es así:

Hasta los banqueros que dejaron la economía mundial y sus propias empresas al borde de la ruina recibieron jugosas bonificaciones.

(Joseph E. Stiglitz. El País, 17 de junio de 2012)

Recibido: 30/10/2012

Revisado: 04/12/2012

Aceptado: 05/03/2013

Disponible on line: 16/04/2013

\section{Resumen}

La economía desregulada ha dado muestras ya de desgarros sociales que van contra el modelo social. Destruido éste, al quedar en segundo plano la cohesión social como objetivo político, quedan las personas en procesos de exclusión social, si no ya excluidas, y con desatenciones que agrietan más aún, si cabe, la brecha heredada por un comportamiento obsesionado de búsqueda del beneficio. No será lo política quien se ocupe de estas heridas, al haber situado a la economía en el primer lugar. Solo actuarán de barrera frente al desmoronamiento de la equidad social los flujos solidarios existentes en la sociedad. Entre ellos, la economía social es un eje motor que nace de la solidaridad y construye cohesión social en la creación de riqueza.

Palabras clave: teoría neoliberal, mercado, modelo social.

\begin{abstract}
Economic deregulation has already caused tears in the social fabric threatening our social model. Once it is destroyed, as social cohesion is no longer a main objective of Policies, many people are in process of social exclusion, if not excluded, and neglected, increasing even more the inherited gap, created by an obsessive pursuit of profit.

It is unlikely that politics will address these social injuries, consequence of placing the economy above all. Only solidarity flows within our societies will be able to act as a barrier to avoid the collapse of social equity. The engine of these flows is social economy; born out of solidarity can help building social cohesion while creating wealth.
\end{abstract}

Keywords: neoliberal theory, market, social model.

Referencia normalizada: De Castro Sanz, M. (2013): «Equidad, cohesión y economía social». Cuadernos de Trabajo Social, 26(1): 31-41.

Sumario: 1. ¿Está pasando lo que está pasando? 2. El modelo social europeo. 3. Equidad social y cohesión social. 4. Las soluciones. 5. La economía social. 6. Su valor social e institucional. 7. Referencias bibliográficas. 


\section{1. ¿Está pasando lo que está pasando?}

Vivimos en estos momentos una situación social y económica compleja y oscura. La crisis ha envuelto todo y todo se entiende desde la crisis. Nada se comprende fuera de la crisis. Se impone como «pensamiento único» que determina y condiciona cualquier enfoque que pretenda revitalizar mecanismos o aspectos sociales donde las personas signifiquen algo más que la economía. Hablar de modelo social, con este manto oscuro que envuelve la sociedad, tiene el riesgo de ser interpretado como una nueva utopía fuera de contexto. Pero es en este aspecto donde se plantea la presente reflexión, procurando romper la forzada forma de entender la sociedad que proyecta poner la economía en el eje motor del pensamiento social. Si esa proyección se realizara, quedarían fuera de la visión política los aspectos cualitativos del entramado social que procuran que las personas excluidas del sistema productivo (o que no se ajustan a él) puedan ocupar su espacio en la sociedad. Por el contrario, la realidad muestra que existen flujos sociales de solidaridad grupal que ponen - no solo lo intentan-límites a esa exclusión, necesariamente acompañada de fractura social.

Cuando se escriben estas líneas (mediados de junio de 2012) se acaba de conocer una ayuda de la Unión Europea en forma de crédito de hasta 100.000.000.000 euros dirigida a sanear al sistema financiero español. No sabemos aún las condiciones que comportará, pero es de suponer que se exigirán mayores esfuerzos a la población. Unos días antes el Ministro de Economía dijo que calcula que en 2016 el déficit público estará en cero. Pero lo que no se dice nunca (quizá porque tampoco lo han pensado) es cómo y en qué condiciones estará la sociedad, la cohesión social y la equidad después de los recortes y precariedades que ya está soportando; cómo estará el empleo y cómo las personas, que tienen derecho a vivir con dignidad. Sabiendo que, si llegar a cero es deseo del Gobierno, llegar al 3 por ciento en 2014 (o en
2015, si nos da Europa un año más) es obligación marcada por la Unión Europea y que la Troika (BCE, FMI y UE) vigilará con especial atención.

No parece mucho pedir que el Gobierno piense también en el desarrollo del modelo social. Ya en 1812, la Constitución de Cádiz decía en su art. $4^{\circ}$ que, «La Nación está obligada a conservar y proteger por leyes sabias y justas la libertad civil, la propiedad y los demás derechos legítimos de todos los individuos que la componen». Era más contundente en el artículo 13: «El objeto del Gobierno es la felicidad de la Nación, puesto que el fin de toda sociedad política no es otro que el bienestar de los individuos que la componen». La Constitución actual también define derechos y deberes de todos los ciudadanos, que el Gobierno debería respetar, y en ningún momento habla de la economía como eje político de la vida ciudadana. Sin embargo, se planifica cómo estará el déficit en 2016, pero no cómo estará la sociedad.

No es difícil imaginarlo. Ya hay en España casi cinco millones de desempleados. La velocidad que está teniendo la destrucción de empleo es pavorosa. Desde el 2007 se han destruido 3.250.000 empleos en España (en el último año se han destruido $493.468^{1}$ ). El equipo de Analistas Financieros Internacionales (AFI) ${ }^{2}$ y el Banco Bilbao Vizcaya (BBVA) ${ }^{3}$ prevén que se perderá un millón de puestos entre 2012 y 2013 y el Gobierno ha dicho que el desempleo crecerá en esta legislatura ${ }^{4}$. Si se desea que en 2014 el déficit sea del 3 por ciento y, además, se piensa que el consumo público caerá un 11 por ciento, es muy seguro que el empleo público también se tambalee. El líder de Comisiones Obreras ha adelantado que el desempleo estará en el 27 por ciento en 2013. La Fundación de Cajas de Ahorro (FUNCAS) considera que «el severo ajuste del déficit público que deben realizar las administraciones públicas (...) induce una espiral descendiente de la actividad económica»» ${ }^{5}$. Nos dice el Ministro de

1 http://www.nuevatribuna.es/articulo/economia/hay-493-468-parados-mas-respecto-a-junio-de-2011dice-ccoo/20120703130713077767.html

2 http://economia.elpais.com/economia/2012/04/28/actualidad/1335649649_526085.html

3 http://economia.elpais.com/economia/2012/02/08/actualidad/1328700285_771443.html

4 http://www.cantabria.ccoo.es/comunes/recursos/5/doc103389_Resumen_de_prensa._Parte_1.pdf

5 http://economia.elpais.com/economia/2012/04/28/actualidad/1335649649_526085.html 
Economía que la recesión está siendo más fuerte de lo previsto (El País, 2 de julio de 2012). Y la recesión trae pobreza y desamparo social. AFI piensa que hasta 2018 no se bajará del 20 por ciento de desempleo. El Gobierno ha dicho a Bruselas que en 2015 estaremos en el 22,5 por ciento de desempleo y la OCDE piensa que hasta el 2026 habrá en España tasas altas de paro ${ }^{6}$.

Por otra parte, los que perdieron el empleo y ya son mayores (mayor, para encontrar empleo se es a partir de 40 años) se han invadido de desesperanza. Más de 400.000 personas ya no acuden a los servicios públicos de empleo ${ }^{7}$ y 1.600.000 personas no reciben ninguna ayu$\mathrm{da}^{8}$. Personas que ya no cuentan en las estadísticas del desempleo, pero que viven, están ahí, nadan en la desesperanza, y se han revestido de pobreza y marginalidad, disfraces que desafortunadamente no depondrán.

El Comité técnico de la Fundación Foessa y Cáritas hablan de que el aumento de la pobreza en España es alarmante (Foessa, 2012). El 22 por ciento de los hogares españoles vive por debajo del umbral de la pobreza, lo que sitúa a España entre los países con las tasas más elevadas, dentro de la Unión Europea. Aumentó más de dos puntos en menos de dos años (de 2009 a 2011), sobre todo en hogares con menores, cuyos sustentadores principales son, en muchos casos, jóvenes. El aumento de la pobreza, está íntimamente relacionado con el incremento de la desigualdad ${ }^{9}$. A la par que la pobreza crece, los derechos sociales básicos decrecen. Los sucesivos recortes experimentados en 2011 agravan la situación, dejando a la población más vulnerable con los servicios básicos mínimos, gravemente mermados. Las expectativas no son esperanzadoras. Las políticas de recortes (centradas normalmente en lo social) han hundido muchas acciones del Tercer Sector paliativas de desgarros sociales, lo que probablemente agudizará los niveles de pobreza y su crecimiento en España ${ }^{10}$. No parece razonable ni pensar ni esperar que la solución para una sociedad más equitativa proceda del sistema.

Es, pues, posible intuir cómo estará la sociedad española en el 2016. Lo más impactante es que los esfuerzos públicos estarán en los recortes y no en la contención de una cohesión y equidad social que se desmoronan. Las personas sufrirán exclusión social, incluso quienes no sospecharon que caerían en la cuneta de la precariedad. Y lo peor es que están sin expectativas de solución, salvo la aportada por la solidaridad social, cuyos apoyos económicos también están siendo recortados, constituyendo un círculo que se encierra en sí mismo.

\section{El modelo social europeo}

Un modelo social es todo el sistema de relaciones que se desea para la sociedad según la primacía de valores que esa misma sociedad anhela (Comisión Europea, 2007, La política de cohesión: 2007-2013). No se habla de economía sino de relaciones sociales, para las que la economía deviene en instrumento de su realización, no en eje político primordial. La economía está (o ha de estar) al servicio del modelo social que se busca. Si se habla, entonces, de un «modelo social europeo» no es tanto por lo que se refiere a la organización de la economía como por el patrón de sociedad definido, que, en los países de la Unión Europea se identifica con el concepto de «Sociedad del Bienestar». Ese bienestar universaliza derechos básicos para la vida: sanidad, educación, participación política y ciudadana, etc. Ludolfo Paramio (2009) dice que:

El argumento central (...) es que si cabe hablar de «modelo europeo» no es tanto en lo que se refiere a la organización de la economía, si-

\footnotetext{
${ }^{6} \mathrm{http} / /$ www.empleofuturo.com/info/la-ocde-preve-tasas-de-paro-altas-en-espana-hasta

7 http://www.empleofuturo.com/articulos/pt/desempleo/espana

$8 \mathrm{http} / /$ www.empleofuturo.com/info/16-mill-de-desempleados-no-reciben-prestaciones

9 Como expresión del abuso en desigualdades sociales es necesario hacer referencia al texto de Stiglitz que encabeza este artículo. En España los directivos de empresas ganaron en 2010 un 134 por ciento más que el salario promedio (como sueldos medios, pues las desviaciones de los más altos sobre los más bajos representan porcentajes mucho más elevados). Son desigualdades inadmisibles desde la óptica de la equidad y la cohesión social.

${ }_{10}$ http://www.pobrezamundial.com/alarmante-crecimiento-de-la-pobreza-en -españa/
} 
no en lo que podríamos llamar el modelo de sociedad. En Europa occidental se parte del reconocimiento de unos derechos sociales de ciudadanía que debe garantizar el Estado. La idea de que el Estado debe ser un «Estado de Bienestar», de que existe una responsabilidad pública en la creación y el mantenimiento de la igualdad de oportunidades y la cohesión social, es lo que tienen en común las sociedades europeas, independientemente de que se haya llegado a esta idea desde historias e ideologías distintas, de que esté plasmada con mayor o menor éxito en los distintos países, y de que se haya visto sometida a las presiones de la economía globalizada y competitiva».

\section{Es decir:}

En un escenario de crecientes desigualdades en el mundo, la Unión Europea, que ha de ser algo más que mercado y moneda, es también un referente por su capacidad de crecimiento y desarrollo, compatibles con la cohesión y con los derechos. Por ello, la equidad social ha de ser concebida como un elemento imprescindible para el crecimiento económico, para la propia competitividad, más en un escenario en el que el gasto público social por habitante se viene ralentizando (Benito Valenciano, 2006).

\section{El Consejo Económico y Social Europeo} (CESE, 2006) indica que:

El modelo social europeo debería transmitir la idea de un espacio de prosperidad democrático, ecológico, competitivo, solidario y socialmente inclusivo para todos los ciudadanos de Europa (...) el modelo social europeo de hoy día se compone básicamente de tres bloques principales: objetivos económicos, objetivos sociales y objetivos medioambientales. Es en la interacción de estos tres sectores - en el contexto de tendencias como la globalizacióndonde tiene lugar el desarrollo concreto del modelo social. La fuerza del modelo social europeo ha venido determinada por la forma en que han interactuado la competitividad, la solidaridad y la confianza mutua (...). El modelo ha demostrado su valor al servir de fuente de inspiración para los países europeos en la construcción de sociedades cohesionadas, solidarias y competitivas... La tarea, hoy, consiste en dar contenido al modelo social y prepararse para el futuro... En este contexto, conviene destacar la relación entre eficacia económica, por un lado, y justicia y cohesión social, por otro (...). Un modelo social tiene que ser dinámico o de lo contrario se petrifica y perece. El modelo social europeo debe ponerse a prueba y discutirse en el marco de un proceso democrático continuo. Hay que hacer evaluaciones y desarrollar y afinar los instrumentos de gobernanza convenientes.

Pero la realidad demuestra que la economía no se somete a ser instrumento sino que aspira a ser eje de valoración política, lo que en la práctica constituye un serio obstáculo para la realización del modelo social deseado, que no se realiza como está diseñado. ¿Qué decir del desempleo en Europa?, ¿de sus fracturas sociales o de la acogida a los inmigrantes?, ¿ de la consolidación de situaciones de pobreza como expresión de la exclusión social? ¿ y qué de la cohesión o descohesión social? ¿Se puede hablar de cohesión cuando importantes grupos sociales quedan expuestos al rigor de quien no tiene nada? La Estrategia de Lisboa deseaba un crecimiento económico unido a la cohesión social, de la que se tratará más adelante. Pero esto no se ha realizado como se planificó; la crisis, que actualmente se vive, ha puesto de manifiesto los desgarros que se provocan considerando a la economía eje de la política y dejando a un lado lo que no es economía.

La sociedad francesa (recuérdese el asunto de Clichy-Sous-Bois 2005; El País, 19 de abril 2012), posteriormente la griega y actualmente casi toda Europa (EE.UU., Japón, etc.) han experimentado la explosión social de grupos que han dicho «basta ya» a situaciones de desequilibrio social insoportable ${ }^{11}$. Es la revuelta de «los indignados», unas veces expresada en signos de violencia (Francia) y otras (las más) en una planificada y exquisita acción pacífica

${ }^{11}$ Como señala Noelia Seibane (2009): «Su violencia era la válvula de escape de una frustración por la que, de alguna manera, están pasando las actuales generaciones jóvenes, pues su actuación no corresponde en absoluto con los cánones en que han sido socializados (...) Su precaria situación, su alejamiento de las instituciones y la preminencia de los valores neoliberales, llevan a los jóvenes a instalarse fuera de la ciudadanía y situarse en zona de serio riesgo de exclusión, así como a la necesidad urgente de un replanteamiento de la noción de ciudadanía». 
cargada de razonamientos. En España así es el movimiento del $15 \mathrm{M}$, extendido por otros países con la misma filosofía ${ }^{12}$. Esto está ocurriendo por haber ocupado la economía el papel preponderante en las prioridades políticas, que no le correspondía.

El Consejo Económico y Social Europeo ya pensaba en 2006 (antes de la crisis actual) que se estaba descomponiendo la cohesión social, que había debilidades y fracasos en el modelo social europeo (desempleo, pobreza, exclusión social...) que era preciso revisar para corregir sus condicionantes ${ }^{13}$. Ya se apuntaba entonces (ahora con mayor motivo) que la pobreza era y es la principal amenaza para el modelo social europeo:

La pobreza infantil es especialmente escandalosa, al destruir oportunidades en la vida y perpetuar las desigualdades de una generación a otra. Las políticas de cohesión social en los Estados miembros no han logrado acabar con la pobreza ni con el desempleo, y ello a pesar de las grandes ambiciones que existen actualmente en este terreno. Se trata de una de las grandes tareas que hay por delante.

Este desacople entre lo planeado y lo real debe (debería) ser un tema de reflexión política profunda de forma que quienes tienen la responsabilidad de gobernar asuman soluciones y generen políticas públicas que aporten mayor cohesión social, creando espacios para todos los ciudadanos sin exclusión. Pero esta reflexión no se da, al menos no se ve. Lo que entraña algunos significados profundos, especialmente cuando han existido encuentros de muy alto nivel político, a escala mundial, para abordar soluciones a la crisis financiera actual generada por el abusivo comportamiento de una economía desregulada, aportando recursos económicos de ayuda a las instituciones financieras (importantes causantes de la crisis) que nunca aparecieron para solucionar objetivos sociales planteados por los gobernantes de los países más desarrollados, como los Objetivos del Milenio en la lucha contra el hambre ${ }^{14}$.

Europa ha trabajado en la definición de su modelo social que ahora se desdibuja con la excusa de la austeridad necesaria para equilibrar las cuentas. Mientras el BCE se preparó para extender un nuevo cheque de cientos de miles de millones de euros a los bancos, su director afirmaba que los países endeudados en exceso han de aplicar una política de austeridad extrema ${ }^{15}$, lo que no sería cuestionable si ello no actuara contra la cohesión social. El profesor Baylos afirma que, a pesar de haberse trabajado el diseño del modelo social, la prevalencia de la economía ha difuminado el empeño y ha vaciado el contenido ${ }^{16}$. Pero no es cierto que la solución a la crisis actual pase necesariamente por la austeridad y los recortes sociales. Hay más teorías económicas, y distintas, que defienden lo contrario ${ }^{17}$. El mercado

12 La página italiana de Facebook y de Twitter Italian Revolution precisa que «nace para abrazar y apoyar al movimiento español Democracia Real Ya»: http://ecorepublicano.blogspot.com.es/2011/05/un-centenar-de-jovenes-claman-en-roma.html. Véase también, Le Monde Diplomatique 201, Julio 2012: «Radiografía de la indignación planetaria».

13 Casi una de cuatro personas en la Unión Europea estaba amenazada con la pobreza o la privación social en 2010; 115.000 .000 personas el 23 por ciento de la población de la Unión fue clasificado como pobre o en situación de necesidad social. Las principales causas son el desempleo, la vejez y los bajos salarios. Conclusión de un informe oficial de la Comisión Europea presentado en Diciembre. http://www.wsws.org/es/articles/2012/jan2012/eseu-j23.shtml

14 Desafortunadamente, también el hambre se ha convertido en negocio. Véase Felipe L. Aranguren (2012). El negocio del hambre. La especulación con alimentos. Madrid: Icaria.

15 Philippe Mabille, director adjunto de La Tribune, escribía en Press-Europe: «El modelo social europeo ha muerto». Según Mario Draghi, exbanquero de Goldman Sachs y nueva figura de comendador de la moneda en Europa, no hay «escapatoria» posible a la aplicación de políticas de austeridad muy duras en todos los países endeudados en exceso y esto implica renunciar a un modelo social basado en la seguridad del empleo y en una redistribución social generosa. «Ese modelo, en el que Europa ha basado su prosperidad desde la Segunda Guerra Mundial, ha desaparecido». Véanse:

http://www.presseurop.eu/es/content/article/1555351-draghi-entierra-el-modelo-social-europeo

http://online.wsj.com/article/SB10001424052970203960804577241221244896782.html

$16 \mathrm{http}: / / \mathrm{www}$. sinpermiso.info/textos/index.php?id=3743\# 
ha demostrado su inoperancia social y su involución social: España está peor que en los años treinta, dice Krugman ${ }^{18}$.

\section{Equidad social y cohesión social}

Son dos pilares fundamentales del modelo social: la equidad y la cohesión. Expresan el equilibrio entre las personas, entre las condiciones de vida y en las relaciones sociales. Son claves para dar a cada uno lo que merece. No son nuevos los conceptos de equidad y de cohesión social, están enlazados con el precepto exclusivamente jurídico de Ulpiano ${ }^{19}$, en sus Tria Praecepta Iuris (tres principios del derecho): suum cuique tribuere (dar a cada uno lo suyo).

En marzo del 2000, los Presidentes de los países de la Unión Europea se reunieron en Lisboa y plantearon una estrategia de desarrollo y crecimiento que, más tarde, se conocería como la «Estrategia de Lisboa» ${ }^{20}$. En ella se decía que:

La Unión se ha fijado un nuevo objetivo estratégico para la próxima década: convertirse en la economía basada en el conocimiento más competitiva y dinámica del mundo, capaz de crecer económicamente de manera sostenible con más y mejores empleos y con mayor cohesión social.

Era muy importante este objetivo, pues unía crecimiento económico y cohesión social, y ello basado en la sostenibilidad y en la necesaria generación de empleo. Estaban las variables imprescindibles para la argamasa de una sociedad integrada y equitativa. Se constataba, en el fondo, que otra forma de crecer económicamente era posible y deseable. Pero el propósito comenzó a nublarse cuando líderes económicos y empresariales comenzaron a decir que la coyuntura estaba un poco negra, que el asun- to de la cohesión social debería de esperar, etc., o simplemente se omitía en sus declaraciones. Les gustaba lo de conseguir una «economía más competitiva y dinámica», pero menos 10 de la sostenibilidad; la cohesión social ni se citaba $^{21}$. Era lógico, ¿cómo iba a intervenir en el desarrollo económico una variable que no era reconocida entre las que tradicionalmente habían regido el impulso de la economía? La cohesión social y el compromiso por el empleo dependerían siempre de la coyuntura económica, según ellos, pues siempre fueron una derivada de la actividad económica. Los políticos callaban mientras tanto.

¿Quién construye cohesión social? ¿Quién se ocupa de ella con el empeño que ocupan los condicionamientos de la economía? La Coordinadora de Ongs para el Desarrollo ha pedido a los gobiernos que luchen contra la pobreza con la misma fuerza que lo hacen para tapar los desastres actuales del sistema financiero. Y no es una demanda extrema la que se hace cuando los responsables del actual desastre financiero salen de sus sedes, dejando por detrás averías que el dinero público deberá solucionar. Qué se puede pensar de un sistema económico en que tan solo,

[Las] cinco mayores firmas financieras de Wall Street (Merrill Lynch, JP Morgan, Lehman Brothers, Bear Stearns y Citigroup) pagaron más de tres mil millones de dólares en los últimos años a sus máximos ejecutivos, justo en el periodo en que éstos se dedicaron a inflar las cuentas, empaquetando en fondos y otros activos opacos préstamos incobrables que han derivado en la mayor crisis financiera de la historia?(...) Los ejecutivos han salido por la puerta de atrás pero con las carteras llenas(...) El salario directivo ha subido un 45 por ciento en los últimos diez años. El del trabajador, un 7 por ciento (El País, 12 de octubre de 2008).

17 Véanse, entre otros libros: Paul Krugman (2012); Navarro, Torres y Garzón (2012). Este último texto, descargable en: http://juantorreslopez.com/wp-content/uploads/Espana-necesita.pdf

${ }_{18}$ El País, 3 de julio, 2012

19 Preceptos Fundamentales de Ulpiano: «Los preceptos del derecho son: vivir honestamente, no dañar a nadie y da a cada uno lo que es suyo».\# Honestae Vivere; \# Alterum Non Laedere; \# Suum Cuique Tribuere. (Ulpiano, 1946).

${ }^{20}$ http://ec.europa.eu/archives/growthandjobs_2009/pdf/lisbon_strategy_evaluation_es.pdf

${ }^{21}$ Olvidaban que «las comunidades con recursos variados de redes sociales y asociaciones cívicas se encuentran en una posición más sólida para hacer frente a la pobreza y la vulnerabilidad, resolver disputas y sacar partido a oportunidades nuevas» (Putnam, 2003). 
Stiglitz dice, en el texto que introduce este artículo, que, «Durante la «recuperación» de 2009 y 2010 , el 1 por ciento de los estadounidenses con mayores ingresos se quedó con el 93 por ciento del aumento de la renta». La cohesión social ¿habrá de esperar?

\section{Las soluciones}

No es el sistema el que aportará las soluciones, ni es posible esperar a que éstas vengan de la «mano invisible» de un mercado, que no solo no se «auto-ordena» sino que da evidentes muestras de desorden y fractura social, dividiendo a la sociedad entre los que tienen cada vez tienen más y los que no tienen nada y cada vez tienen menos. Tampoco es de esperar la solución de los organismos internacionales, ni de la propia estructura de Gobierno de la Unión Europea. Ya se han definido por una gestión orientada hacia la satisfacción y normalización de los mercados, a sabiendas de que éstos no se sacian fácilmente y urdirán nuevas estrategia para invadir espacios públicos con signos de rentabilidad. En Madrid se está diseñando la privatización del agua y se han dado pasos en esta dirección en la sanidad y en la educación; en diversas comunidades autónomas la sanidad ya la gestionan empresas privadas y la educación está sufriendo descalabros privatizadores.

La idea de que el Estado se reduzca al mínimo, tan demandada por los planteamientos neoliberales, tiene ya recorridos de difícil vuelta atrás. Los recortes se han centrado en las políticas y en los servicios sociales, que algunos poderes públicos califican de insoportables económicamente. Algunos centros especiales de empleo ya han cerrado y también ONG, otras están en trance de cierre. La lucha contra la drogodependencia - tan difícil de conseguir - o la atención a las mujeres maltratadas han sido de las primeras actividades que se han recortado en algún gobierno autonómi- co. También sufre importantes restricciones la atención a la discapacidad. Como si en ello existiera despilfarro económico y, lo que es peor, sin medir la aportación a la cohesión social de estas actividades sociales. Porque este aspecto no es valorable.

Es la hora de que la sociedad hable, de que se organice y de que la creatividad social, nacida de la solidaridad, comience a aportar soluciones, como siempre lo ha hecho al percibir espacios sociales desatendidos por el sistema y necesitados de «acogida» para neutralizar la exclusión social. Solo desde esta fuerza renovadora, la solidaridad social, se podrán aportar mecanismos de inserción social y laboral. Los ejes de funcionamiento de la Economía Social y del Tercer Sector se centran, precisamente, en la urgencia de generar riqueza colectiva, equitativamente distribuida y enraizada en el territorio. Es otra forma de emprender.

\section{La economía social}

La economía social es una forma de reacción colectiva que nace para paliar las heridas provocadas en la sociedad por la acción de un mercado que actúa sin normas. En España se ha aprobado recientemente una ley que identifica los valores y cualidades de esta forma de reaccionar. El valor de esta ley es definir los contenidos del concepto y las figuras jurídicas que pertenecen a la economía social. En su artículo 2, la ley dice:

Se denomina economía social al conjunto de las actividades económicas y empresariales, que en el ámbito privado llevan a cabo aquellas entidades que, de conformidad con los principios recogidos en el artículo 4, persiguen bien el interés colectivo de sus integrantes, bien el interés general económico o social, o ambos. ${ }^{22}$

El profesor Monzón, presidente de CIRIEC-España, apunta que:

22 Ley 5/2011, de 29 de marzo, de Economía Social.

Artículo 4. Principios orientadores. Las entidades de la economía social actúan en base a los siguientes principios orientadores:

a) Primacía de las personas y del fin social sobre el capital, que se concreta en gestión autónoma y transparente, democrática y participativa, que lleva a priorizar la toma de decisiones más en función de las personas y sus aportaciones de trabajo y servicios prestados a la entidad o en función del fin social, que en relación a sus aportaciones al capital social.

b) Aplicación de los resultados obtenidos de la actividad económica principalmente en función del trabajo aportado y servicio o actividad realizada por las socias y socios o por sus miembros y, en su caso, al fin social objeto de la entidad. 
El actual interés por las fórmulas empresariales propias de la Economía Social se deriva de la creciente sospecha de que viejos y nuevos problemas que afectan a nuestras sociedades no pueden resolverse satisfactoriamente con la exclusiva acción de empresas capitalistas, empresas públicas y sector público en general. Son problemas de desempleo, distribución de la renta, calidad de los servicios públicos, vivienda, sanidad, educación, calidad de vida de la población jubilada, etc. (Monzón y Defourny 2000).

La economía social viene a poner soluciones a las grietas que la economía desregulada genera en la sociedad. Aquí reside la importancia de estas empresas y lo imprescindible que son para la cohesión social.

El Consejo Económico y Social Europeo (Dictamen REX/325, 2007) expresa la importancia de la Economía Social en Latinoamérica y, por extensión, allá donde se precisen acciones de desarrollo local, todo lo que plantea es perfectamente prolongable a nuestro país, de forma especial en los sectores sociales más desfavorecidos. Define a la Economía Social como:

Conjunto de empresas privadas organizadas formalmente, con autonomía de decisión y libertad de adhesión, creadas para satisfacer las necesidades de sus socios a través del mercado, produciendo bienes y servicios, asegurando o financiando y en las que la eventual distribución entre los socios de beneficios o excedentes así como la toma de decisiones, no están ligados directamente con el capital o cotizaciones aportados por cada socio, correspondiendo un voto a cada uno de ellos (...) La Economía Social también agrupa a aquellas entidades privadas (...) que producen servicios de no mercado a favor de las familias, cuyos excedentes, si los hubiera, no pueden ser apropiados por los agentes económicos que las crean, controlan o financian.

Los profesores españoles Monzón, Barea y Chaves, del Centro Internacional de investigación e información sobre la Economía pública, social y cooperativa (CIRIEC), piensan que la Economía Social es un:

Conjunto de empresas privadas organizadas formalmente, con autonomía de decisión y libertad de adhesión, creadas para satisfacer las necesidades de sus socios a través del mercado, produciendo bienes y servicios, asegurando o financiando, y en las que la eventual distribución entre los socios de beneficios o excedentes, así como la toma de decisiones, no están ligados directamente con el capital o cotizaciones aportadas por cada socios, correspondiendo un voto a cada uno de ellos (CIRIEC, 2006).

\section{Su valor social e institucional}

- El citado Dictamen del Comité Económico y Social Europeo (CESE) afirma la aportación incuestionable de la economía social en la construcción de variables creadoras de la cohesión social:

Fomentando la Economía Social y Solidaria (ESS), de más intenso carácter empresarial, se incide en objetivos basados en los principios de la solidaridad y no se prioriza el aumento de beneficios, participando más en la consecución del bienestar general. Por otra parte, la ESS con mayor componente de transformación sociopolítica asume que las empresas deben ser eficientes y obtener beneficios, creando redes que les permitan sostenerse en el mercado. Por ello, la ESS no debe instalarse en la economía de la pobreza, sino del cambio de tendencias, asociando desarrollo, eficiencia económica y justicia social para erradicar asimetrías de todo tipo (...) $\mathrm{La} \mathrm{OIT}^{23}$ reconoce el papel de la ESS pues los valores y principios en que se basan sus empresas incluyen el respeto por los principios y derechos fundamentales en el trabajo... La importancia, como meta, de establecer parámetros mínimos de cohesión social es considerada esencial para cualquier planteamiento de desarrollo. Los gobiernos locales están dándose cuenta de la importancia de apoyar a los emprendedores de la ESS para revitalizar las comunidades rurales y urbanas.

c) Promoción de la solidaridad interna y con la sociedad que favorezca el compromiso con el desarrollo local, la igualdad de oportunidades entre hombres y mujeres, la cohesión social, la inserción de personas en riesgo de exclusión social, la generación de empleo estable y de calidad, la conciliación de la vida personal, familiar y laboral y la sostenibilidad.

d) Independencia respecto a los poderes públicos.

${ }^{23}$ Documento de Trabajo 2011 «Economía social y solidaria: nuestro camino común hacia el Trabajo Decente» en http://socialeconomy.itcilo.org/en/2011-readers. 
- Son empresas generadoras de empleo en condiciones de mayor estabilidad que el creado por el mercado y resuelven, gracias a la capacidad colectiva de reaccionar, crisis sectoriales o territoriales. En otro Dictamen, el Comité ${ }^{24}$ dice que,

Las PYME y las empresas de economía social son instrumentos esenciales de empleo y reempleo en el contexto de las importantes transformaciones industriales que se están produciendo desde los sectores en declive y en los que se reduce el empleo hacia sectores tradicionales (artesanía, oficios) y otros en expansión, como los servicios a las empresas, las NTIC, los sectores de alta tecnología, la construcción y las obras públicas, los servicios de proximidad (incluida la salud) y el turismo.

- Son empresas generadoras de inclusión laboral y social. El Comité Europeo de las Regiones $^{25}$ dice que

La economía social (...) establece una nueva cultura empresarial del sector social... orientada principalmente hacia la integración de los grupos de población marginados a través de la participación activa con el fin de crear empleo.

- Transforman comportamientos sociales pasivos en activos, al desarrollar capacidades emprendedoras en las personas y fomentadoras del desarrollo local. El citado Dictamen del Comité Europeo de las Regiones apunta:

$\mathrm{Al}$ organizar a los desempleados a nivel local, ayuda a las autoridades locales a transformar un sistema pasivo de prestaciones de seguridad social y desempleo en una inversión social activa a favor del desarrollo sostenible.

- Generan capital social al establecer relaciones de confianza entre las personas. El mismo Dictamen del Comité Europeo de las Regiones dice:

La economía social proporciona un valor añadido al proceso de desarrollo local y al pro- greso social; permite la constitución de un capital social a nivel local gracias la establecimiento de unas relaciones de confianza y de un espíritu comunitario, al compromiso cívico y la participación en la sociedad, así como al fomento de una mayor cohesión social que permite reintegrar a la personas excluidas y marginados (por ejemplo, los grupos de inmigrantes, los desempleados de larga duración).

— Por todo ello, son importantes «socios» o colaboradores de los poderes locales. El citado Dictamen del Comité Europeo de las Regiones afirma que,

Las empresas de economía social son socios importantes de las autoridades locales a la hora de elaborar estrategias de desarrollo local y de instaurar una nueva protección social pluralista a nivel local... podrán colmar el vacío en materia de bienes y servicios de carácter social cuya producción o provisión no estén cubiertas por los operadores del mercado tradicional ni por las autoridades.

- Responden a comportamientos nacidos de la solidaridad a través de la acción empresarial:

Sus valores básicos son: solidaridad, cohesión social, responsabilidad social, gestión democrática, participación y autonomía (...) pertenece a un conjunto de cuatro familias: cooperativas, mutualidades, asociaciones y fundaciones.

- El Congreso de diputados español, en el informe elaborado para la Subcomisión de Responsabilidad Social Empresas, confirma la participación de la economía social en la construcción social:

Las acciones de Economía Social conllevan diversas virtualidades (...) creando empleo estable en mayores proporciones que el generado por el mercado; enraíza a las personas en sus territorios naturales (...) (una empresa de economía social no se va del territorio donde está); genera riqueza allá donde el inversor tradicional

${ }^{24}$ Dictamen sobre «Capacidad de adaptación de las PYME y de las empresas de economía social los cambios impuestos por el dinamismo económico».

http://eur-lex.europa.eu/LexUriServ/LexUriServ.do?uri=OJ:C:2005:120:0010:0016:ES:PDF

25 Dictamen sobre «Asociaciones entre las autoridades locales y las organizaciones socioeconómicas: contribución al empleo, al desarrollo local y a la cohesión social». 
no tiene motivaciones para existir (...); desarrolla el espíritu emprendedor (...); son escuelas de democracia económica (...) demuestra situarse en una tradición de clara sintonía con la filosofía de fondo de la RSE (...) así como de abrir nuevos espacios económicos más acordes con la sensibilidad ética de la sociedad, en este momento se puede citar: la acción empresarial para insertar laboralmente a personas excluidas que el mercado laboral tradicional nunca integraría; el fomento de la sensibilidad social para la integración cívica y económica de personas con discapacidad, hasta ahora ignoradas por el mercado tradicional (...) la activación y promoción de las finanzas éticas...

De todo ello se deduce que la economía social es una fuerza de contención necesaria que evita (o aminora) las consecuencias sociales de un mercado desbaratador de la cohesión social. Si los gobiernos estuvieran interesados en una sociedad cohesionada la reconocerían como aliado natural.

\section{Referencias bibliográficas}

Aranguren, F.L. (2012). El negocio del hambre: La especulación con alimentos. Barcelona: Icaria.

Benito Valenciano, R. (2006). El modelo social europeo, una referencia fundamental de la Unión Europea. Revista de Derecho Social, 36, 229-234.

Chomsky, N. y Ramonet, I. (2010). Cómo nos venden la moto. Barcelona: Icaria.

CIRIEC. (diciembre, 2006). Manual para la elaboración de las cuentas satélites de las empresas de economía social. Estudio realizado para la Comisión Europea. Madrid: Ciriec.

Comín, A. y Gersavoni, L. (coords.) (2012). Democracia económica: Hacia una alternativa al capitalismo. Barcelona: Icaria.

Comisión Europea. (2007). La política de cohesión 2007-2013. Comentarios y textos oficiales. Luxemburgo: Oficina de Publicaciones Oficiales de las Comunidades Europeas.

Comité de las Regiones. (2002). Dictamen sobre Asociaciones entre las autoridades locales y las organizaciones socioeconómicas: contribución al empleo, al desarrollo local y a la cohesión social. (2002/C 192/13).

Comité Técnico de la Fundación FOESSA. (coord.) (2012). Exclusión y desarrollo social: análisis y perspectivas 2012. Madrid: Cáritas Española. Recuperado de: http://www.caritas.es/imagesrepository/CapitulosPublicaciones/4314/EXCLUSION por ciento20Y por ciento20DESARROLLO por ciento20SOCIAL. por ciento20Versi por cientoC3 por cientoB3n por ciento20digital.pdf.

Consejo Económico y Social Europeo. (20 de mayo 2005). Dictamen sobre Capacidad de adaptación de las PYME y de las empresas de economía social los cambios impuestos por el dinamismo económico. 2005C/120/03. Diario Oficial de las Comunidades Europeas 20/5/2005.

Consejo Económico y Social Europeo (6 de julio de 2006). Dictamen sobre Cohesión social: dar contenido a un modelo social europeo (Dictamen de iniciativa). Diario Oficial de la Unión Europea (973/2006) EN-MP/EGR/MIG/gf/sz/rf.

Consejo Económico y Social Europeo. (22 de febrero de 2012). Dictamen «La economía social en América Latina». Dictamen REX/325 La economía social en América Latina. Bruselas: CESE.

Felber, C. (2012). La economía del bien común: un modelo económico propuesto por Christian Felber que supera la dicotomía entre capitalismo y comunismo para maximizar el bienestar de nuestra sociedad. Barcelona: Deusto.

Krugman, P. (2012). Acabad ya con esta crisis. Barcelona: Crítica.

Ley 5/2011, de 29 de marzo, de Economía Social. Boletín Oficial del Estado, 76, (30 de marzo de 2011). pp. 33023-33033.

Monzón, J.L. y Deforuny, J. (2000). La economía social, entre economía capitalista y economía pública. Santiago de Chile: Universidad de Chile.

Monzón, J.L. y Deforuny, J. (2000). La economía social: tercer sector de un nuevo escenario. Recuperado de: http://www.unida.org.ar/Bibliografia/documentos/M4 por ciento20ONG por ciento20y por ciento20DL por ciento20Bs por ciento20As/Economia por ciento20Social por ciento20Monzon por ciento20Defourny.doc) 
Navarro, V., Torres López, J. y Garzón Espinosa, A. (2012). Lo que España necesita: una réplica con propuestas alternativas a la política de recortes del PP. Barcelona: Deusto.

OIT. (2011). Economía social y solidaria: nuestro camino común hacia el Trabajo Decente Documento de Trabajo 2011

Organización Internacional del Trabajo. (2011).Economía social y solidaria: nuestro camino común hacia el Trabajo Decente. Disponible en http://socialeconomy.itcilo.org/en/2011-readers.

Paramio, L. (2009). El modelo europeo: ¿modelo económico o modelo social? Nueva Sociedad, 221, 166-179.

Putnam, R.D. (2003). El declive del capital social: Un estudio internacional sobre las sociedades y el sentido comunitario. Barcelona: Galaxia Gutenberg.

Seibane, Na (2009). Juventud y exclusión social. En J.F. Tezanos (ed.), Temas para el debate (177178). Madrid: Sistema.

Ulpiano (1946). Reglas. Madrid: CSIC. 